\title{
CLOROFILA E CAROTENOIDES EM MARACUJAZEIRO- -AMARELO IRRIGADO COM ÁGUAS SALINAS NO SOLO COM BIOFERTILIZANTE BOVINO ${ }^{1}$
}

\author{
LOURIVAL FERREIRA CAVALCANTE ${ }^{2}$, THIAGO JARDELINO DIAS 3 , \\ RONALDO NASCIMENTO ${ }^{4}$, JOSÉ LUCÍNIO DE OLIVEIRA FREIRE 5
}

\begin{abstract}
RESUMO - Os efeitos deletérios provocados pelo estresse salino resultam em modificações nos mecanismos bioquímicos e fisiológicos das plantas, alterando, dentre outros, os teores foliares de clorofila e carotenoides, comprometendo a atividade fotossintética e, consequentemente, o crescimento, o desenvolvimento, a produção e a adaptabilidade aos ambientes adversos. O objetivo do trabalho foi avaliar os efeitos de diferentes condutividades elétricas da água de irrigação (CEai), associadas às épocas de aplicação de biofertilizante, sobre os teores de pigmentos fotossintéticos para a determinação dos pigmentos cloroplastídicos (clorofila $a, b$, total e carotenoides) do maracujazeiro-amarelo. Os tratamentos foram distribuídos em arranjo fatorial $5 \times 4$, referentes aos valores de CEai: 0,$5 ; 1,5 ; 2,5 ; 3,5$ e $4,5 \mathrm{dS} \mathrm{m}^{-1}$, em quatro épocas de aplicação do biofertilizante: sem biofertilizante (SB); aplicação uma semana antes do transplantio (1SAT); a cada 90 dias, a partir do transplantio (90DAT); uma semana antes e a cada 90 dias, após o transplantio (1SAT+90DAT). O aumento da concentração salina da água de irrigação reduziu a eficiência fotossintética nas folhas do maracujazeiro-amarelo, sendo mais drástico na condutividade superior a 2,5 $\mathrm{dS} \mathrm{m}^{-1}$. As frequências de aplicação do biofertilizante não influenciaram nas concentrações dos pigmentos fotossintéticos.
\end{abstract}

Termos para indexação: Passiflora edulis, pigmentos fotossintéticos, salinidade, efluente orgânico.

\section{CHLOROPHYLL AND CAROTENOIDS IN YELLOW PASSION FRUIT PLANTS IRRIGATED WITH SALINE WATER ON SOIL WITH BOVINE BIOFERTILIZER}

\begin{abstract}
The deleterious effects caused by salt stress result in changes in the physiological and biochemical mechanisms of plants, changing, among others, the levels of chlorophyll and carotenoids, affecting the photosynthetic activity and hence growth, development, production and adaptability to adverse environments. The study aimed to evaluate the effects of irrigation water with increasing salinity levels and the application frequency of biofertilizer on the concentration of the photosynthetic pigments (chlorophyll $\mathrm{a}, \mathrm{b}$, total and carotenoids) of the yellow passion fruit. The experiment was designed in a $5 \mathrm{x} 4$ factorial corresponding to the levels of electrical conductivity (EC) of the irrigation water of $0.5 ; 1.5 ; 2.5 ; 3.5$ and $4.5 \mathrm{dS} \mathrm{m}^{-1}$ and to four frequencies of the application of bovine biofertilizer: no biofertilizer (WB); application of bovine biofertilizer one week before transplanting (1WBT); bio-fertilizer application every 90 days after transplanting (90DAT); and bovine bio-fertilizer applied one week before and every 90 days after transplanting (1WBT+90DAT). Increased salinity of irrigation water reduced the photosynthetic efficiency in leaves of yellow passion fruit, being more drastic in the conductivity above $2.5 \mathrm{dS} \mathrm{m}^{-1}$. The frequency of application of biofertilizer did not influence the photosynthetic pigments content.
\end{abstract}

Index terms: Passiflora edulis, photosynthetic pigments, salinity, organic effluent.

\footnotetext{
${ }^{1}$ Trabalho Sinfruit 014 - Simpósio Internacional de Fruticultura - Avanços na Fruticultura (17 a 21 Outubro) Parte da tese de Doutorado do segundo autor (PPGA/CCA/UFPB), pesquisa financiada pelo Conselho Nacional de Desenvolvimento Científico e Tecnológico (CNPq); ${ }^{2}$ Departamento de Solos e Engenharia Rural, CCA/UFPB, Areia - PB, Brasil, 58397-000. E-mail: lofeca@cca.ufpb.br;

${ }^{3}$ Pós-Graduação em Agronomia, Centro de Ciências Agrarias/UFPB, Areia - PB, Brasil, 58.397-000. E-mail: tjardelino@hotmail.com; ${ }^{4}$ Departamento de Engenharia Agrícola, CCTRN/UFCG, Campina Grande - PB, Brasil, 58429-900. E-mail: ronaldo@deag.ufcg.edu.br; ${ }^{5}$ Instituto Federal de Educação, Ciência e Tecnologia (IFPB), Câmpus Picuí, Picuí - PB, Brasil, 58.187-000. E-mail: lucinio@folha.com.br.
} 


\section{INTRODUÇÃO}

A expansão das áreas agrícolas em todo o mundo, associada à elevada demanda por alimentos e de águas de boa qualidade têm gerado a necessidade do uso de águas de qualidade inferior na agricultura, principalmente nas regiões semiáridas do mundo e do Brasil, onde a água de irrigação, quase sempre, possui concentração salina que compromete a exploração agrícola (MALHASHI et al., 2008; CAVALCANTE et al., 2010).

A irrigação com água de elevados teores de sais solúveis limita o crescimento e o desenvolvimento da maioria das plantas cultivadas, dentre as quais, o maracujazeiro-amarelo, que é sensível à salinidade (AYERS; WESTCOT, 1999). O acúmulo de sais no solo, além de alterar as propriedades físicas e químicas do meio edáfico, reduz o potencial osmótico da solução do solo, restringindo a disponibilidade de água, resultando em desbalanço nutricional e toxidade, prejudicando os processos metabólicos e fisiológicos, dentre os quais, a fotossíntese (PAK et al., 2009). Santos. (2004) afirma que altas concentrações de sais nas folhas inibem a síntese de ácido 5-aminolevulinato, que é a molécula precursora da clorofila, promovem alterações no processo respiratório, na assimilação do nitrogênio e no metabolismo de proteínas (PARIDA et al., 2004; MUNNS; TESTER, 2008).

Apesar da elevada sensibilidade do maracujazeiro-amarelo à ação dos sais, como enfatizado por Ayers e Westcot (1999), as pesquisas sobre a adoção de técnicas que mitiguem os efeitos danosos nas salinidade nas culturas, mesmo não sendo frequentes, já são disponibilizadas na literatura. Nesse sentido, Silva et al. (2008), Asik et al. (2009) e Aziz et al. (2011) constataram que as substâncias húmicas, oriundas de compostos orgânicos, estimularam o crescimento de goiabeira (Psidium guajava), a eficiência fotossintética do trigo (Triticum durum) e a absorção de nutrientes de uma planta nativa do Egito (Matthiola incana), respectivamente, todas sob irrigação com águas salinas de condutividade elétrica igual e até superior a $6 \mathrm{dS} \mathrm{m}^{-1}$.

Especificamente para a cultura do maracujazeiro-amarelo irrigado com águas salinas, Freire et al. (2010) e Dias et al. (2011) concluíram que o aumento da salinidade da água de 0,5 para até $4,5 \mathrm{dS}$ $\mathrm{m}^{-1}$ resultou em perdas de produção e de qualidade dos frutos, mas sempre com menor intensidade nas plantas desenvolvidas no solo com biofertilizante. Essa situação evidencia que as substâncias húmicas não eliminam, mas atenuam os efeitos depressivos da salinidade às plantas.

Os compostos bioativos, como os biofertili- zantes, exercem efeitos positivos na atenuação da agressividade dos sais às plantas, pois atuam como fonte de energia para a microbiota (SILVA JÚNIOR et al., 2009) exercerem melhora na estrutura e aeração do solo (MELLEK et al. (2010), estimularem a redução do potencial osmótico no interior do sistema radicular, contribuindo para a absorção de água e ajustamento osmótico das plantas no meio salino (BAALOUSHA et al., 2006; LACERDA et al., 2010).

Pelo exposto, o trabalho teve como objetivo avaliar os efeitos de diferentes níveis de salinidade das águas de irrigação, e da frequência de aplicação de biofertilizante no solo, sobre os teores de pigmentos clorofiláticos em plantas de maracujazeiro-amarelo.

\section{MATERIAL E MÉTODOS}

O experimento foi desenvolvido em pomar de maracujazeiro-amarelo instalado no município de Remígio-PB, a $6^{\circ} 53^{\prime} 00^{\prime \prime} \mathrm{S}, 36^{\circ} 02^{\prime} 00^{\prime \prime} \mathrm{W}$, com altitude de $470 \mathrm{~m}$. De acordo com o sistema de Köeppen, adaptado ao Brasil (COELHO; SONCIN, 1982), o clima da região é do tipo As', quente e úmido com temperatura média, umidade e precipitação durante o período de 2008 e 2009 , de $24,8^{\circ} \mathrm{C}, 74,8 \%$ e 956,5 $\mathrm{mm}$, respectivamente.

As plantas avaliadas foram distribuídas em blocos casualizados, em parcelas subdivididas, com três repetições e nove plantas por parcela, sendo estudados os efeitos de cinco níveis de salinidade da água de irrigação (condutividade elétrica (CEai): 0,$5 ; 1,5 ; 2,5 ; 3,5$ e $\left.4,5 \mathrm{dS} \mathrm{m}^{-1}\right)$ e quatro frequências de aplicação do biofertilizante: sem biofertilizante (SB), aplicação uma semana antes do transplantio das mudas (1SAT), a cada 90 dias após o transplantio (90DAT) e uma semana antes e a cada 90 dias após o transplantio (1SAT+90DAT).

O plantio foi realizado em baldes plásticos com 60 e $50 \mathrm{~cm}$ de altura e diâmetro, utilizados como lisímetros de pressão, com capacidade para $158 \mathrm{dm}^{3}$ e drenos na base final inferior. Os lisímetros foram preenchidos com $130 \mathrm{dm}^{3}$ de material dos 10 $\mathrm{cm}$ superficiais de um cambissolo húmico distrófico de textura arenosa e esterco bovino $(\mathrm{C} / \mathrm{N}=18 / 1)$, nas proporções de 9:1 (solo:esterco bovino), cuja caracterização quanto à salinidade está indicada na Tabela 1

Diariamente, procedeu-se a irrigação das plantas com cada tipo de água pelo método de aplicação localizada por gotejamento, aplicando lâminas $20 \%$ maiores do que a da evapotranspiração de referência do dia anterior, obtida com base na evaporação de Tanque "A" (GONDIM et al., 2009).

O biofertilizante bovino foi produzido por fer- 
mentação anaeróbia conforme Santos e Akiba (1996), sendo, após maturação (fermentação) e imediatamente antes de cada aplicação, diluído em água não salina (CEai $\leq 0,5 \mathrm{dS} \mathrm{m}^{-1}$ ), na proporção de 1:1 e fornecido em volume correspondente a $10 \%$ do volume do substrato (SOUSA et al., 2008). O biofertilizante, por ter sido aplicado ao solo diluído em água, foi analisado como de água para irrigação (Tabela 1).

No início da segunda floração (448 dias após o transplantio das mudas), foram coletadas as folhas completamente expandidas ( $4^{\text {a }}$ folha) do ramo terciário, na região mediana do maracujazeiro, para a determinação dos pigmentos cloroplastídicos (clorofila $a, b$, total e carotenoides). As folhas foram imediatamente acondicionadas em envelopes de alumínio, armazenadas em recipientes térmicos com isolamento contendo gelo químico e transportadas imediatamente para o laboratório.

Em seguida, com o auxílio de um vazador circular, foram retirados círculos de tecido vegetal do terço médio das folhas, procedendo-se à pesagem de cada material. Posteriormente, o material foi macerado e colocado em recipientes revestidos com papel-alumínio, adicionando-se $25 \mathrm{ml}$ de acetona $80 \%$. Os recipientes ficaram sob refrigeração $\left(8^{\circ} \mathrm{C}\right)$ por 24 horas e, posteriormente, foram filtrados em papel durante 5 minutos (ARNON, 1945). As leituras de absorbâncias foram obtidas por espectrofotometria nos comprimentos de onda de 470 $\left(\mathrm{A}_{470}\right), 647\left(\mathrm{~A}_{647}\right)$ e $663 \mathrm{~nm}\left(\mathrm{~A}_{663}\right)$, utilizando-se acetona a 80\% como branco. Na quantificação da clorofila $a, b$, total e carotenoides, foram utilizadas as equações descritas por Lichtenthaler (1987).

Os dados foram submetidos à análise de variância, pelo teste F 5\% de probabilidade, comparação de médias Tukey, por regressão polinomial, utilizando-se do programa SAS versão 8.0 (SAS, 2000).

\section{RESULTADOS E DISCUSSÃO}

O aumento da salinidade das águas de 0,5 para até $2,5 \mathrm{dS} \mathrm{m}^{-1}$ não comprometeu o processo fotossintético do maracujazeiro-amarelo, como evidenciam os teores de clorofila de $a, b$, total e razão entre os valores de clorofila $a / b$ (Figura 1 ). Entretanto, a irrigação com águas de condutividade elétrica superior a $2,5 \mathrm{dS} \mathrm{m}^{-1}$, como as de $3,5 \mathrm{e} 4,5 \mathrm{dS} \mathrm{m}^{-1}$, inibiu significativamente as variáveis estudadas. A tendência dos dados está em consonância com o verificado por Pak et al. (2009), que o aumento da salinidade das águas comprometeu a produção fotossintética em plantas de trigo.

Apesar da ausência de efeitos significativos entre as águas de 0,$5 ; 1,5$ e 2,5 $\mathrm{dS} \mathrm{m}^{-1}$, os teores da clorofila $a$, clorofila $b$ e total aumentaram até os valores de 1,32 $\mathrm{mg} \mathrm{g}^{-1}$ (Figura 1A), 0,50 $\mathrm{mg} \mathrm{g}^{-1}$ (Figura 1B) e $1,83 \mathrm{mg} \mathrm{g}^{-1}$ (Figura $1 \mathrm{C}$ ) referentes às salinidades máximas estimadas das águas de 0,$71 ; 1,42 \mathrm{e}$ $0,5 \mathrm{dS} \mathrm{m}^{-1}$. Por outro lado, ao relacionar os valores médios das duas últimas com os das três primeiras, percebe-se que os aumentos da salinidade das águas inibiram em 37,2; 25,6 e 34,6\% os teores de clorofila $a, b$ e total, respectivamente. Verifica-se também que a elevação do teor salino das águas de 0,5 para 4,5 $\mathrm{dS} \mathrm{m} \mathrm{m}^{-1}$ reduziu em $12,6 \%$ os valores da relação entre clorofila $a$ e $b$ (Figura 1D). Efeitos semelhantes foram obtidos por Parida et al. (2004) e Santos (2004) após constatarem que a irrigação com água salina inibiu a eficiência fotossintética de mangrove (Bruguiera parviflora) e girassol.

Ao considerar que o maracujazeiro-amarelo, conforme Ayers e Westcot (1999), é sensível aos sais, os declínios da clorofila estão compatíveis com o aumento da salinidade das águas. Além dos efeitos negativos sobre o processo fotossintético, Freire et al. (2010) e Dias et al. (2011) concluíram que o aumento da concentração salina das águas de irrigação de 0,5 para $4,5 \mathrm{dS} \mathrm{m}^{-1}$ provocou redução na capacidade produtiva do maracujazeiro-amarelo, na beleza plástica e na espessura da casca dos frutos. Os declínios nos teores de clorofila, conforme Santos (2004) e Munns e Tester (2008), são resultados dos desequilíbrios nas atividades fisiológicas e bioquímicas promovidas pelo teor de sais, além do tolerado pelas culturas. Para os respectivos autores, o excesso de sais estimula a atividade enzimática da clorofilase que degrada as moléculas do pigmento fotossintetizante e induz a destruição estrutural dos cloroplastos, provocando também o desbalanceamento e perda de atividade das proteínas de pigmentação.

A ausência do composto orgânico e as distintas frequências de aplicação não interferiram nos teores de clorofila $a, b$ e total do maracujazeiro-amarelo (Figura 2). Os valores de clorofila $a$ variaram de 1,02 a $1,19 \mathrm{~g} \mathrm{~kg}^{-1}$ (Figura 2A), os de clorofila $b$ de 0,42 a $0,47 \mathrm{mg} \mathrm{g}^{-1}$ (Figura 2B) e os de clorofila total de 1,47 a 1,66 $\mathrm{mg} \mathrm{g}^{-1}$ Figura, 2C), sendo representados pelos valores médios de 1,08, 0,44 e 1,53 $\mathrm{mg} \mathrm{g}^{-1}$ de matéria fresca foliar. Comparativamente, os dados da clorofila $a$ são inferiores à variação de 1,13 a 1,68 $\mathrm{mg} \mathrm{g}^{-1}$, mas os da clorofila $b$ superam a oscilação de 0,14 a $0,31 \mathrm{mg} \mathrm{g}^{-1}$ obtidas por Freire (2011), em maracujazeiro-amarelo sem e com biofertilizante bovino aplicado ao solo na forma líquida.

A ausência de diferenças significativas entre os dados de clorofila, obtidos das plantas sem biofertilizante e com o insumo fornecido nas diferentes frequências, pode ser resposta de as plantas estarem, 
por ocasião da amostragem, aos 448 dias após o transplantio, adequadamente supridas em nitrogênio $\left(44,44 \mathrm{~g} \mathrm{~kg}^{-1}\right)$, potássio $\left(37,43 \mathrm{~g} \mathrm{~kg}^{-1}\right)$, magnésio $\left(3,06 \mathrm{~g} \mathrm{~kg}^{-1}\right)$ e enxofre $\left(4,43 \mathrm{~g} \mathrm{~kg}^{-1}\right)$ na matéria seca foliar (MALAVOLTA et al., 1997). Os pigmentos clorofiláticos, conforme Viana e Kiehl (2010), em trigo, são influenciados pelo estado nutricional das plantas; o que significa declínios ou incrementos se estão com carência ou adequadamente supridas com os respectivos nutrientes.

Os teores de carotenoides não sofreram interferência do aumento de salinidade das águas de irrigação, no solo sem e com o biofertilizante bovino fornecido em distintas frequências de aplicação (Figura 3).

Os carotenoides são pigmentos que, durante a fotossíntese, podem desempenhar duas funções distintas: absorção de luz nos complexos de captação de luz atuando como pigmentos acessórios e exercendo ação fotoprotetora do aparato fotoquímico (KERBAUY, 2004), prevendo danos foto-oxidativos às moléculas de clorofila (RAVEN et al., 2007).

Ao considerar a baixa variação entre os dados, apesar de a cultura ser sensível à salinidade, a aplicação dos tratamentos não exerceu efeitos suficientes para provocar a degradação de $\beta$-caroteno e promover a redução da síntese de zeaxantina, pigmentos estruturais dos carotenoides, aparentemente envolvidos na proteção da clorofila (XU et al., 2001; EPSTEIN; BLOOM, 2006 MUNNS; TESTER, 2008)

TABELA 1- Situação salina do substrato e do biofertilizante bovino.

\begin{tabular}{ccccccccccc}
\hline $\mathrm{pH}$ & $\mathrm{CE}$ & $\mathrm{RAS}$ & $\mathrm{Ca}^{2+}$ & $\mathrm{Mg}^{2+}$ & $\mathrm{K}^{+}$ & $\mathrm{Na}^{+}$ & $\mathrm{SO}_{4}^{2-}$ & $\mathrm{CO}_{3}^{2-}$ & $\mathrm{HCO}_{3}^{-}$ & $\mathrm{Cl}^{-}$ \\
& $\mathrm{dS} \mathrm{m}^{-1}$ & $\left(\mathrm{mmol} \mathrm{L}^{-1}\right)^{1 / 2}$ & \multicolumn{7}{c}{ Substrato } \\
\hline 7,72 & 7,84 & 6,94 & 10,25 & $11,63 \quad 14,79$ & 40,04 & 7,41 & 1,82 & 14,52 & 53,67 \\
\hline \multicolumn{8}{c}{ Biofertilizante } \\
6,55 & 2,76 & 3,41 & 4,13 & $7,02 \quad 7,98$ & 8,03 & 5,08 & ALD & 1,12 & 21,81 \\
\hline
\end{tabular}

A

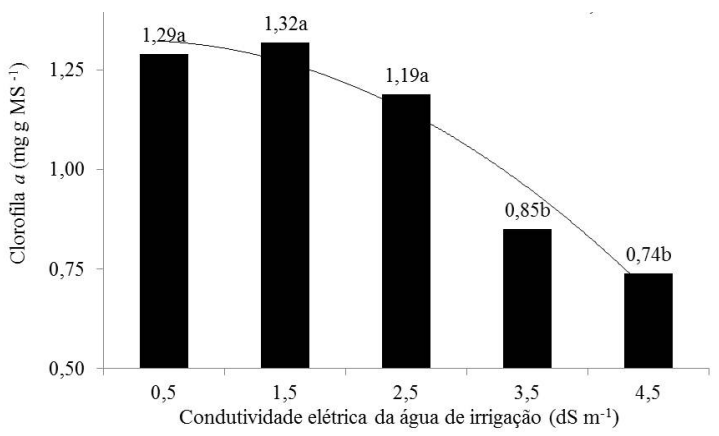

C

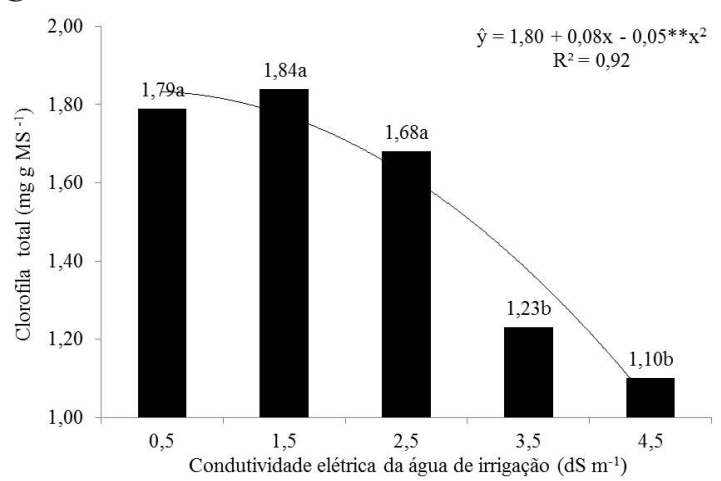

B

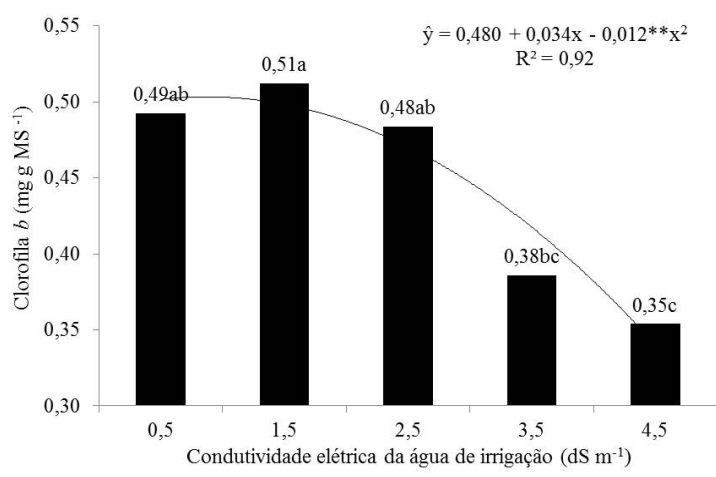

D

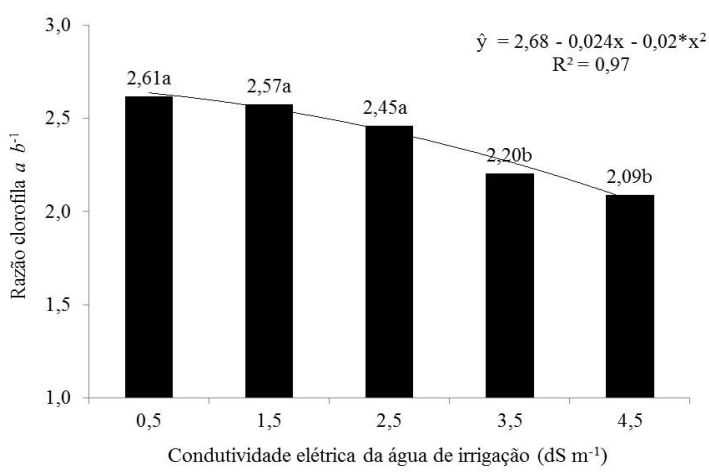

FIGURA 1- Teores de clorofila $a$ (A), clorofila $b$ (B), clorofila total (C) e razão clorofila $a: b$ (D) em folhas de maracujazeiro-amarelo irrigado com águas salinas. As médias seguidas pelas letras minúsculas não diferem entre si, pelo teste de Tukey, a 5\% de significância. 

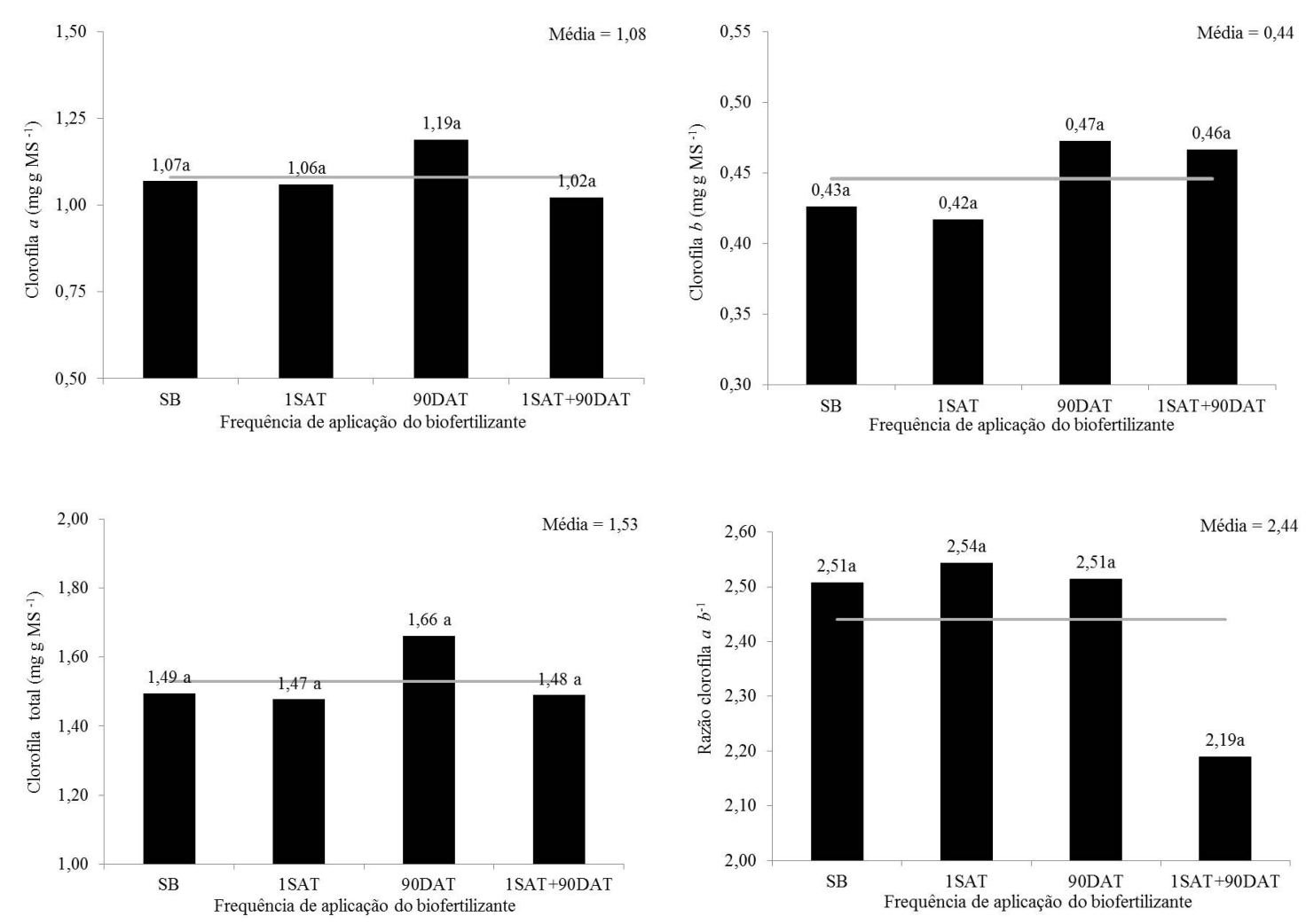

FIGURA 2 - Teores de clorofila $a$ (A), clorofila $b$ (B), clorofila total (C) e razão clorofila $a: b$ (D) em folhas de maracujazeiro-amarelo, em diferentes frequências de aplicação de biofertilizante (B). As médias seguidas pelas letras minúsculas não diferem entre si, pelo teste de Tukey, a 5\% de significância.

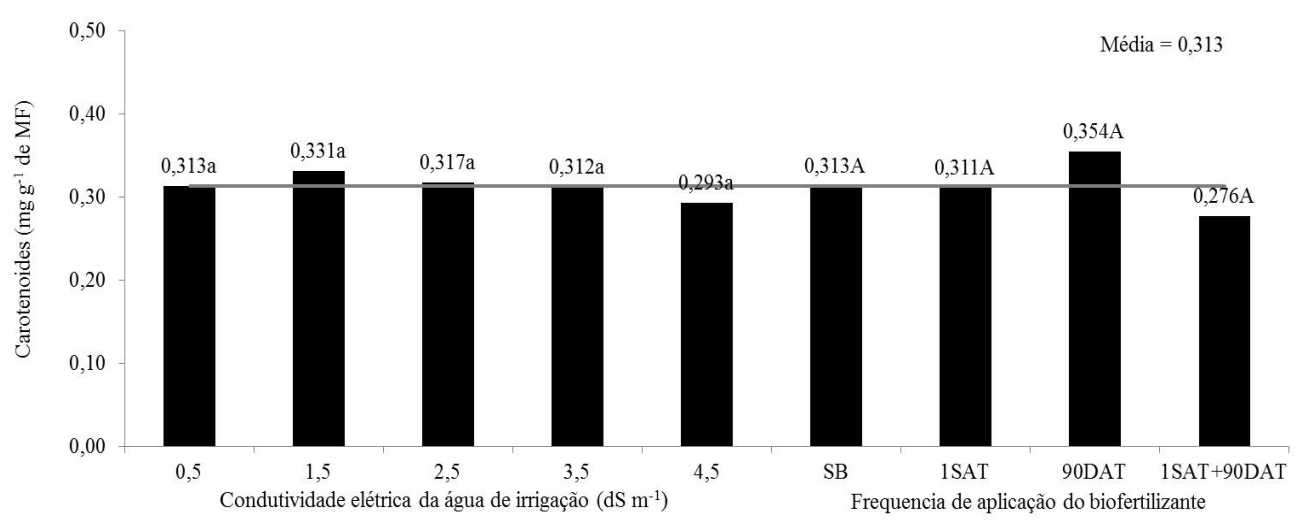

FIGURA 3 - Teores de carotenoides em folhas de maracujazeiro-amarelo irrigado com águas salinas em diferentes frequências de aplicação de biofertilizante. Médias seguidas pelas letras minúsculas (CEai) e maiúsculas (frequência de aplicação do biofertilizante) não diferem entre si, pelo teste de Tukey, a 5\% de significância. 


\section{CONCLUSÕES}

1-O aumento da salinidade das águas até $2,5 \mathrm{dS} \mathrm{m}^{-1}$ não comprometeu, mas a irrigação do maracujazeiro-amarelo com águas de teor salino acima desse valor diminuiu a eficiência fotossintética das plantas.

2-O biofertilizante bovino, nas frequências de aplicação ao solo na forma líquida, não influenciou na produção de clorofila nem de carotenoides pelas plantas.

\section{REFERÊNCIAS}

ARNON, D.J. Cooper enzymes in isolated chloroplast: Polyphenoloxidase in Beta vulgaris. Plant Physiology, Minneapolis, v.24, n.1, p.1-15, 1945.

ASIK, B.B.; TURAN, M.A.; CELIK, H.; KATKAT, A.V. Effects of Humic Substances on Plant Growth and Mineral Nutrients Uptake of Wheat (Triticum durum cv. Salihli) Under Conditions of Salinity. Asian Journal of Agricultural Research. Malasya, v.1, n.2, p.87-95, 2009.

AYERS, R.S.; WESTCOT, D.W. A qualidade de água na agricultura. 2.ed. Campina Grande: UFPB, 1999, 153p. (FAO Estudos Irrigação e Drenagem, 29)

BAALOUSHA, M.; MOTENICA-HEINO, M.; COUSTUMER, P.L. Conformation and size of humic substances: Effects of major cation concentration and type, $\mathrm{pH}$, salinity and residence time. Colloids and surfaces $A$ : physicochemical and engineering aspects, New York, v.272, n.1-2, p.48-55, 2006.

CAVALCANTE, L.F.; VIEIRA, M.S.; SANTOS, A.; OLIVEIRA, W.M.; NASCIMENTO, J.A.M. Água salina e esterco líquido de bovino na formação de mudas de goiabeira Paluma. Revista Brasileira de Fruticultura, Jaboticabal, v.32, n.01, p.251-261, 2010.

COELHO, M.A.; SONCIN, N.B. Geografia do Brasil. São Paulo: Ed. Moderna, 1982. 368p.

DIAS, T.J.; CAVALCANTE, L.F.; LEON, M.J.; SANTOS, G.P.; ALBUQUERQUE, R.P.F. Produção do maracujazeiro e resistência mecânica do solo com biofertilizante sob irrigação com águas salinas. Revista Ciência Agronômica, Fortaleza. v.42, n.3, p.644-651, 2011.
EPSTEIN, E.; BLOOM, A.J. Nutrição mineral de plantas. Londrina: Planta, 2006. 404p.

FREIRE, J.L.O. Crescimento e desenvolvimento do maracujazeiro-amarelo em solo com biofertilizante sob irrigação com água salina e não salina. 2011. 271f. Tese (Doutorado em Agronomia) - Centro de Ciências Agrárias, Universidade Federal da Paraíba, 2011.

FREIRE, J.L.O.; CAVALCANTE, L.F.; REBEQUI, A.M.; DIAS, T.J.; NUNES, J.C.; CAVALCANTE, I.H.L. Atributos qualitativos do maracujá-amarelo produzido com agua salina, biofertilizante e cobertura morta no solo. Revista Brasileira de Ciências Agrárias, Fortaleza, v.5, n. 1, p.102-110, 2010.

GONDIM, S.C.; CAVALCANTE, L.F.; CAMPOS, V.B.; MESQUITA, E.F.; GONDIM, P.C. Produção e composição foliar do maracujazeiro-amarelo sob lâminas de irrigação. Revista Caatinga, Mossoró, v.22, n. 1, p.100-107, 2009.

KERBAUY, G.B. Fisiologia vegetal. Rio de Janeiro: Guanabara Koogan, 2004. 452p.

LACERDA, C.F.; COSTA, R.N.T.; BEZERRA, M.A.; GHEUI, H.R. Estrategia de manejo para o uso de água salina na agricultura. In: GHEYI, H. R.; DIAS, N. S.; LACERDA, C. F. Manejo da salinidade na agricultura: estudos básicos e aplicados. Fortaleza: INCT Sal, 2010. p. 303-318.

LICHTENTHALER, H.K. Chlorophylls and carotenoids: pigment photosynthetic biomembranes. Methods in Enzymology, New York v.148, p.362385, 1987.

MALASH, N.M.; ALI, F.A.; FATAHALLA, M.A.; KHATAB, ENTSAR A.; HATEM, M.K.; TAWFIC, $\mathrm{S}$. Response of tomato to irrigation with saline water applied by different irrigation methods and water management stratigies. International Journal of Plant Production, Iran, v.2, n.2, p.101-116, 2008.

MALAVOLTA, E.; VITTI, G.C.; OLIVEIRA, S.A. Avaliação do estado nutricional das plantas: princípios e aplicações. 2.ed. Piracicaba: POTAFÓS, 1997. 319p. 
MELLEK, J. E.; DIECKOW, J.; SILVA, V. L.; FAVARETTO, N.; PAULETTI, V.; VEZZANI, F. M.; SOUZA, J. L. M. Dairy liquid manure and no-tillage: Physical and hydraulic properties and carbon stocks in a Cambisol of Southern Brazil. Soil \& Tillage Research, Amsterdam, v 110, p. 69-76, 2010.

MUNNS, R.; TESTER M. Mechanisms of salinity tolerance. Annual Review of Plant Biology. Palo Alto, v. 59, p. 651-681, 2008.

PAK, V.A.; NABIPOUR, M.; MESKARBASHEE, M. Effect of Salt Stress on Chlorophyll Content, Fluorescence, $\mathrm{Na}^{+}$and $\mathrm{K}^{+}$Ions Content in Rape Plants (Brassica napus L.). Asian Journal of Agricultural Research, Malaysia, v.2, n.2, p.28-37, 2009.

PARIDAS, A.K.; DAS, A.B.; MITTRA, B. Effects of salt on growth, ion accumulation photosynthesis and leaf anatomy of the mangrove, Bruguiera parviflora. Trees - Structure and Function, Berlin, v.18, p.167-174, 2004.

RAVEN, P.H.; EVERT, R.F.; EICHHORN, S.E. Biologia vegetal. 7.ed. Rio de Janeiro: Guanabara Koogan, 2007. 728p.

SANTOS, A.C.; AKIBA, F. Biofertilizantes líquidos: uso correto na agricultura alternativa. Seropédica: Imprensa Universitária/UFRRJ, 1996. 35p. SANTOS, C.V. Regulation of chlorophyll biosynthesis and degradation by salt stress in sunflower leaves. Scientia Horticulturae, Amsterdam, v.103, p.93-99, 2004.
SAS. SAS user's guide: statistical analysis system, Release 8.0. Cary, 2000. 544p.

SILVA, A. B. F.; FERNANDES, P. D.; GHEYI, H. R.; BLANCO, F.F. Growth and yield of guava irrigated with saline water and addition of farmyard manure. Revista Brasileira de Ciências Agrárias, Recife. v.3, n.4, p.354-359, 2008.

SILVA JUNIOR, TAVARES, R. C.; MENDES FILHO, GOMES, V. F. F. Efeitos de níveis de salinidade sobre a atividade microbiana de um Argissolo Amarelo incubado com diferentes adubos orgânicos. Revista Brasileira de Ciências Agrárias, Recife, v. 4, n. 4, p. 378-382, 2009.

SOUZA, G.B.; CAVALCANTE, L.F.; CAVALCANTE, I.H.L.; BECKMAN- CAVALCANTE, M.Z.; NASCIMENTO, J.A.M. Salinidade do substrato contendo biofertilizante para a formação de mudas de maracujazeiro irrigado com água salina. Revista Caatinga, Mossoró, v.21, p.172-180, 2008.

VIANA, E.M.; KIEHL, J.C. Doses de nitrogênio e potássio no crescimento do trigo. Bragantia, Campinas, v. 69, n. 4, p.975-982, 2010

XU, H.;VAVILIN, D.; VERMAAS, W. Chlorophyll $\mathrm{b}$ can serve as the major pigment in functional photosystem II complexos of cyanobacteria. Proceedings of the National Academy of Sciences of the USA, Washington, v.98, n.24, 2001. 